\title{
PathTech LIFE: Overview of Findings from a National Survey of Technician Education Students
}

\section{Dr. Will Tyson, University of South Florida}

Will Tyson is an Associate Professor of Sociology at the University of South Florida. Dr. Tyson's research examines STEM educational and career pathways with a focus on student- and institutional-level influences on high school and college science and math course taking and STEM degree attainment. Dr. Tyson was the Principal Investigator of the NSF-funded project "Successful Academic and Employment Pathways in Advanced Technologies" or PathTech (4 years, \$1.2 million). PathTech was a collaboration with Tampa Bay area high schools, community colleges, and local technology and manufacturing industry to better understand pathways from into engineering technology AS degree and certificate programs and back into the local workforce. Dr. Tyson is also the Principal Investigator of the follow-up study PathTech LIFE: Constructing a National Survey of Engineering Technology Students through Regional and Statewide Testing (3 years, \$778,031), a national survey of community college students completing coursework, certificates, and degrees in engineering technology and related technology fields. Dr. Tyson is co-editor of Becoming an Engineer in Public Universities: Pathways for Women and Minorities (2010) based on NSF-funded research in colleges of engineering in Florida universities. Dr. Tyson has published on secondary and post-secondary pathways to engineering and other STEM bachelor's degrees as well as faculty climate in STEM programs.

\section{Dr. Marilyn Barger, National Science Foundation ATE Centers}

Dr. Marilyn Barger is the Principal Investigator and Executive Director of FLATE, the Florida Regional Center of Excellence for Advanced Technological Education, funded by the National Science Foundation and housed at Hillsborough Community College in Tampa, Florida since 2004. FLATE serves the state of Florida as its region and is involved in outreach and recruitment of students into technical career pathways; has produced award winning curriculum design and reform for secondary and post-secondary Career and Technical Education programs; and provides a variety of professional development for SETM and technology secondary and post-secondary educators focused on advanced technologies. She earned a B.A. in Chemistry at Agnes Scott College and both a B.S. in Engineering Science and a Ph.D. in Civil Engineering (Environmental) from the University of South Florida, where her research focused on membrane separation science and technologies for water purification. She has over 20 years of experience in developing curricula for engineering and engineering technology for elementary, middle, high school, and post secondary institutions, including colleges of engineering. Dr. Barger has presented at many national conferences including American Association of Engineering Education, National Career Pathways Network, High Impact Technology Exchange, ACTE Vision, League of Innovation and others. Dr. Barger serves on several national panels and advisory boards for technical programs, curriculum and workforce initiatives, including the National Association of Manufacturers Educators'Council. She is a Fellow of the American Society of Engineering Education, a member of Tau Beta Pi and Epsilon Pi Tau honor societies. She is a charter member of both the National Academy and the University of South Florida's Academy of Inventors. Dr. Barger holds a licensed patent and is a licensed Professional Engineer in Florida.

\section{Dr. Lacksmi Jayaram, University of South Florida}

is a Research Associate at the University of South Florida and Co-Principal Investigator of PathTech LISTEN: Mixed Methods Longitudinal Investigations of Students in Technician Education (NSF \#1801163, 2018-21). Dr. Jayaram has 25 years of experience in education, as a professor, researcher, evaluator, curriculum developer, and program analyst. Dr. Jayaram's research interests include studying the experiences of under-represented and non-traditional groups in STEM fields. 


\section{PathTech LIFE: Overview of Findings from National Survey of Technician Education Students}

Dr. Will Tyson, University of South Florida

Dr. Lakshmi Jayaram, University of South Florida

Dr. Marilyn Barger, Florida Advanced Technological Education Center (FLATE)

ABSTRACT: PathTech LIFE is a national survey of 3,216 students enrolled in technician education programs at 96 two-year colleges across the nation, The survey includes questions about Learning, Interests, Family, and Employment (LIFE) factors that influence student pathways into these programs as well as their educational and career aspirations. The survey included questions about students' sociodemographic background, enrollment status, program satisfaction, campus resource knowledge and utilization, motivation to enroll, career and educational aspirations, employment status, and school-work-life balance issues. Findings reported here can help us learn more about student recruitment, retention, and completion in advanced technology programs at two-year colleges. We also provide a focus on students in Advanced Manufacturing,

\section{Introduction}

This study is a partnership between the University of South Florida, the Florida Advanced Technological Education Center (FLATE) at Hillsborough Community College and national ATE Center Partners. This research is funded through the National Science Foundation (NSF) Advanced Technological Education (ATE) Targeted Research in Technician Education program We administered a national survey to community college students in advanced technology fields in collaboration with a national network of colleges. PathTech LIFE seeks to understand how these Learning, Interests, Family, and Employment (LIFE) experiences of two-year college students impact their decisions to enroll, return for further coursework, and/or pursue a certificate or degree.

\section{Data \& Methods}

The data for this study comes from the PathTech LIFE dataset. PathTech LIFE is a survey study that is part of a trilogy of projects funded by the National Science Foundation (NSF) Advanced Technological Education (ATE) Targeted Research in Technician Education. PathTech is a partnership between University of South Florida, Florida Advanced Technological Education Center (FLATE) at Hillsborough Community College and national ATE Center Partners. We administered a national survey to 3,216 community college students in advanced technology programs across 96 two-year colleges. Overall, the sample shows that technician students are a diverse group, and includes about $20 \%$ women, $30 \%$ racialethnic minorities, $10 \%$ reporting disabilities, 5\% LGBT students, and an age range of 18 to $65+$. Many technician students are also "non-traditional" in higher education settings by way of their life experiences, with the majority simultaneously juggling school, work, and parenthood.

The original pilot survey was constructed by the USF research team with help from an expert panel made up of the FLATE team and two representatives from six other two-year colleges with AS/AAS degree programs in advanced technologies. Most of the expert panel was made up of Principal Investigators from national advanced technologies centers representing the four advanced technology fields represented in this study: advanced manufacturing, engineering technologies, micro and nano technologies, and energy and environmental technologies. Each of the expert panelists were also funded by NSF ATE. These individuals reviewed the instrument and provided feedback following a 
three-stage iterative process known as the Delphi technique in which panelists selected questions to include in the survey. After the first pilot survey was sent to six colleges, the research team analyzed the data and then conducted a "think-aloud" exercise in which four survey respondents were interviewed while completing the survey to get their immediate feedback on the survey. After considering the interview responses, the second pilot was sent to 18 colleges. After shortening the survey from 25 minutes to 15 minutes at the request of community college administrators, the survey was distributed three times in 2017 and 2018 to students at 96 colleges.

\section{Sample}

We used purposive sampling to target two-year college students in advanced manufacturing, engineering technologies, micro and nano technologies, and energy and environmental technologies AS/AAS degree programs. Interested college administrators received recruitment flyers and a link to the survey to pass on to students. In the end, 3,216 students from 96 different colleges in 38 states and three US territories completed the survey.

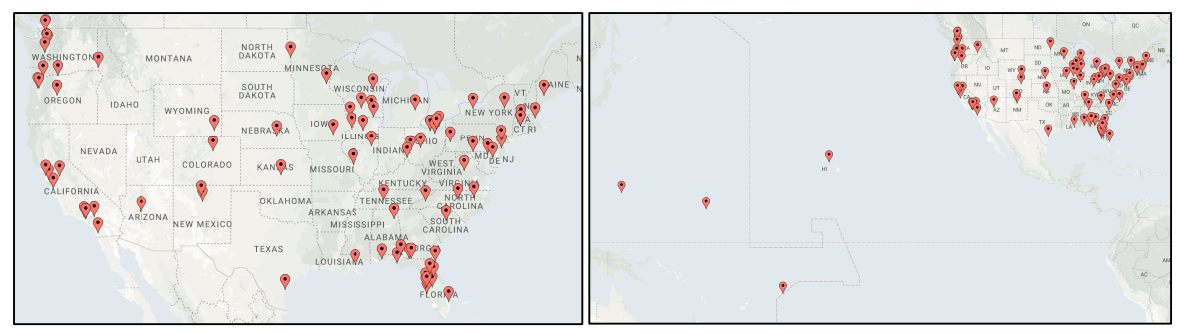

Students jdentified their programs as follows: 53\% Engineering Technology, 19\% Energy/Environment, $19 \%$ Advanced Manufacturing, $2 \%$ Micro/Nano, $19 \%$ None of the Above. It is interesting to note that almost one-fifth of respondents did not identify within a particular program area.

\section{Findings}

\section{Demographic Background}

The majority of students in the study were full-time students -- $63 \%$ of students were full-time while $37 \%$ enrolled part-time. In addition, the majority of students were aged 35 years or younger. When looking at gender, $79 \%$ of students are men, $20 \%$ are women, and $1 \%$ identify as non-gender conforming. Race/ethnicity of the sample is comparable to the US as a whole as shown below. Students were able to select all that apply.

\section{Moved (insertion) [1]}

Deleted: advanced technologies programs across the nation. We sent recruitment flyers and emails to members of the expert panel; then, these individuals forwarded the information to administrators at affiliated programs in the following advanced technologies programs: engineering technology, energy and environmental technology, micro and nanotechnology, and advanced manufacturing. ๆ ๆ

We constructed an online questionnaire (using Qualitrics). To establish content validity, we compiled an expert panel, with two administrators each, from seven two-year college AS/AAS degree programs in advanced technologies. The expert panel included Principal Investigators from national advanced technologies centers representing advanced manufacturing, engineering technologies, micro and nano technologies, and energy and environmental technologies. These individuals reviewed the instrument and provided feedback following a three stage iterative process known as the Delphi technique. In addition, we distributed the questionnaire in a pilot study as well as conducted a think-aloud with six advanced technologies students to provide feedback on the items of the instrument. The questionnaire was designed to capture the sociodemographic profile, life stages, life transitions, and motivating factors of students in advanced technologies programs at two-year colleges. Other sections of the questionnaire included open-ended questions in an attempt to capture information on students' life stages and transitions, demographic items (i.e., age, gender, race/ethnicity, socioeconomic (SES) factors, academic discipline within advanced ... [1]

Moved up [1]: Sample

Deleted: The program composition of

Deleted: $s$

Deleted: broke down this way

Deleted: broke down in the following way in the sample: ... 


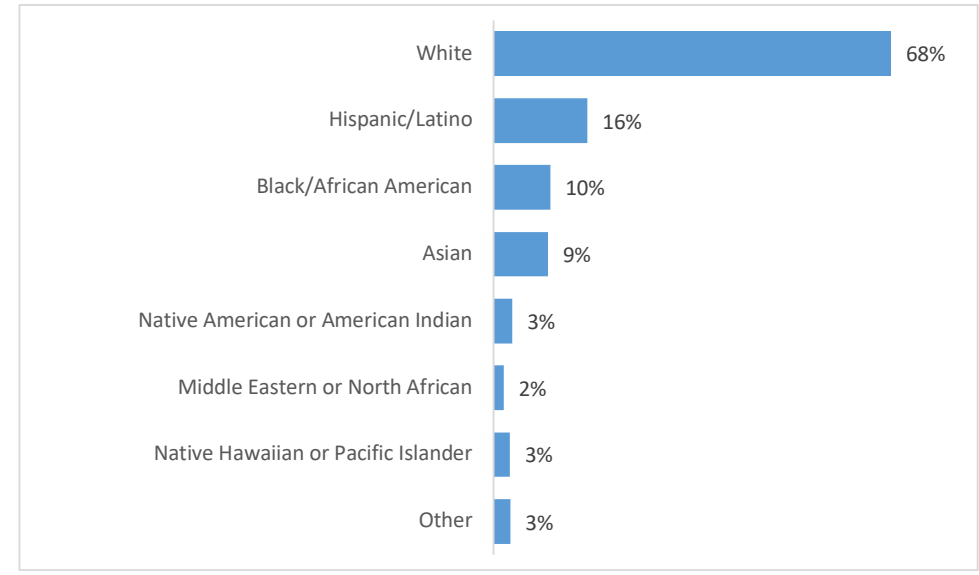

Educational Background and Future Aspirations

We also examined students' educational backgrounds as well as their educational aspirations going forward. For the majority of students, we see that participation in their current program is their first experience in higher education: $58 \%$ had never enrolled in college, $17 \%$ had previously enrolled in community college, $8 \%$ had earned an associate's degree, $10 \%$ had enrolled in a four-year college, and 7\% had earned a Bachelor's degree. Furthermore, when analyzing future educational aspirations, the majority were degree-seeking, with only $10 \%$ reporting that they did not aspire for a degree, $27 \%$ aiming for an associate's degree, 38\% for a Bachelor's degree, and 25\% aspiring for the Masters/PhD level. In addition, $55 \%$ of students in the sample were "extremely committed" and $32 \%$ were "very committed" to stay in the technician field. Taking these findings together, we see that students in this sample are vey committed to both technician education and occupational pathways.

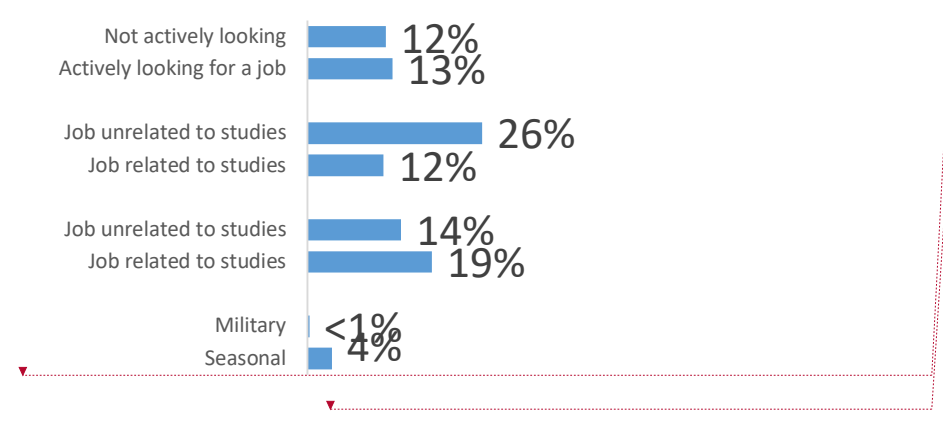

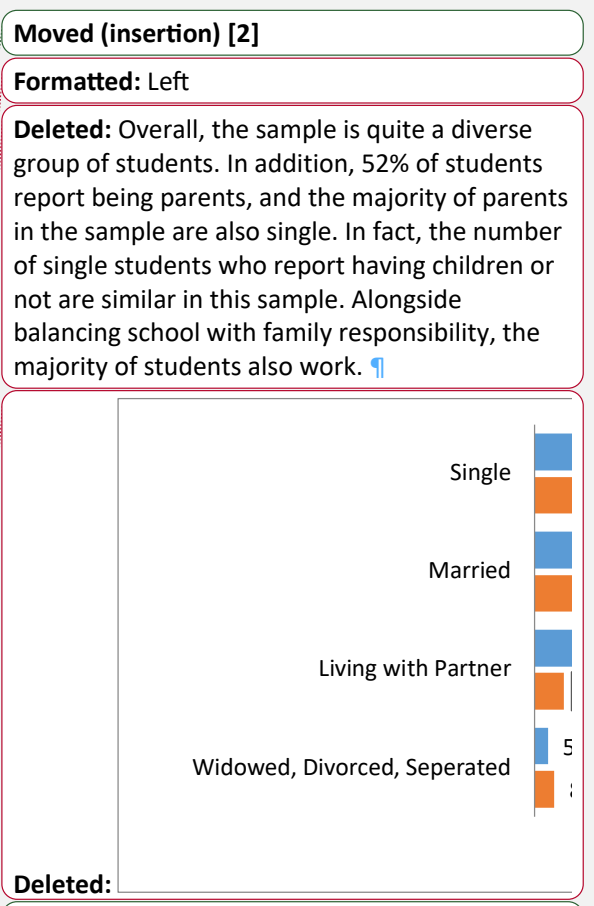

Moved up [2]: Educational Background and Future Aspirations 7

ๆ

We also examined students' educational backgrounds as well as their educational aspirations going forward. For the majority of students, we see that participation in their current program is their first experience in higher education: $58 \%$ had never enrolled in college, $17 \%$ had previously enrolled in community college, $8 \%$ had earned an associate's degree, $10 \%$ had enrolled in a four-year college, and $7 \%$ had earned a Bachelor's degree. Furthermore, when analyzing future educational aspirations, the majority were degree-seeking, with only $10 \%$ reporting that they did not aspire for a degree, $27 \%$ aiming for an associate's degree, $38 \%$ for a Bachelor's degree, and $25 \%$ aspiring for the Masters/PhD level. In addition, $55 \%$ of students in the sample were "extremely committed" and $32 \%$ were "very committed" to stay in the 
When analyzing program satisfaction, we find that the majority of students report being "extremely satisfied" and "very satisfied" with their programs overall, and in particular with their instructors, advising, and in their interactions with other students. Additionally, the majority of students also report that their programs fit their schedules and lifestyles "extremely well" and "very well."

\section{Spotlight on Advanced Manufacturing Students}

Students in the Advanced Manufacturing programs are similar in many ways to the overall sample, such as expressing high degrees of satisfaction with their programs, having similar part-time and full-time enrollment status and educational backgrounds, as well as similarities in family life. However, there are also differences in some key ways. For example, there are more 18-19 year olds in Advanced

Manufacturing in comparison to the overall sample. In addition, there are more men than women. In fact, while the overall sample is composed of $20 \%$ women, only $10 \%$ of students in advanced manufacturing are women. There are also more White students in Advanced Manufacturing in comparison to the overall sample, and comparatively fewer Black, Latino, and Asian students. Another area of key difference has to do with employment. A greater percentage of students in Advanced Manufacturing are working full-time in their field than their peers in other fields, while in the overall sample, a greater percentage of students work full-time in an unrelated field. Lastly, a greater percentage of students in Advanced Manufacturing do not aim to complete a degree or plan to complete an Associate's degree in comparison to the overall sample, where the majority are aiming to complete either an Associate's or Bachelor's degree. Taking these descriptive differences together, we see a younger group of students in Advanced Manufacturing, more men than women, less racial and ethnic diversity, more students working full-time within manufacturing, and lower levels of degree aspirations. 
Comparison of Advanced Manufacturing Students with Full Sample

\begin{tabular}{|c|c|c|c|}
\hline & & $\begin{array}{l}\text { Adv } \\
\text { Manufctrng }\end{array}$ & Total \\
\hline \multirow[t]{2}{*}{ Enrollment status } & Full-time student & $64 \%$ & $63 \%$ \\
\hline & Part-time student & $36 \%$ & $37 \%$ \\
\hline \multirow[t]{5}{*}{ Age Quintiles } & $18-19$ & $27 \%$ & $22 \%$ \\
\hline & $20-21$ & $15 \%$ & $17 \%$ \\
\hline & $22-26$ & $18 \%$ & $21 \%$ \\
\hline & $27-33$ & $17 \%$ & $19 \%$ \\
\hline & $34+$ & $22 \%$ & $21 \%$ \\
\hline \multirow[t]{3}{*}{ Gender } & Male & $89 \%$ & $80 \%$ \\
\hline & Female & $10 \%$ & $20 \%$ \\
\hline & Non-gender conforming & $1 \%$ & $1 \%$ \\
\hline Race/Ethnicity & White & $81 \%$ & $68 \%$ \\
\hline \multirow[t]{7}{*}{ (check all that apply) } & Hispanic/Latino & $11 \%$ & $16 \%$ \\
\hline & Black/African American & $5 \%$ & $10 \%$ \\
\hline & Asian & $4 \%$ & $9 \%$ \\
\hline & Native American or American Indian & $2 \%$ & $3 \%$ \\
\hline & Middle Eastern or North African & $1 \%$ & $2 \%$ \\
\hline & Native Hawaiian or Pacific Islander & $1 \%$ & $3 \%$ \\
\hline & Something else, please specify & $3 \%$ & $3 \%$ \\
\hline \multirow[t]{7}{*}{ Marital status } & Single & $67 \%$ & $66 \%$ \\
\hline & Widowed & $0 \%$ & $0 \%$ \\
\hline & Divorced & $3 \%$ & $3 \%$ \\
\hline & Separated & $1 \%$ & $1 \%$ \\
\hline & Living with a partner & $10 \%$ & $10 \%$ \\
\hline & Married & $20 \%$ & $20 \%$ \\
\hline & Child(ren) in Household & $51 \%$ & $52 \%$ \\
\hline \multirow{10}{*}{ Employment } & Not currently employed and not actively & & \\
\hline & looking & $9 \%$ & $12 \%$ \\
\hline & Not currently employed, but actively & & \\
\hline & looking for a job & $11 \%$ & $13 \%$ \\
\hline & In the military & $0 \%$ & $0 \%$ \\
\hline & Employed seasonally & $3 \%$ & $4 \%$ \\
\hline & $\begin{array}{l}\text { Employed part-time in job unrelated to } \\
\text { studies }\end{array}$ & $25 \%$ & $26 \%$ \\
\hline & $\begin{array}{l}\text { Employed part-time in job related to } \\
\text { studies }\end{array}$ & $14 \%$ & $12 \%$ \\
\hline & Employed full-time in job unrelated to & & \\
\hline & studies & $9 \%$ & $14 \%$ \\
\hline
\end{tabular}




\begin{tabular}{llrr} 
& Employed full-time in job related to & & \\
& studies & $28 \%$ & $19 \%$ \\
\hline Prior Education & Never enrolled & $60 \%$ & $58 \%$ \\
& Enrolled in CC & $19 \%$ & $17 \%$ \\
& Earned Assoc degree & $8 \%$ & $8 \%$ \\
& Enrolled in 4 Year & $8 \%$ & $10 \%$ \\
& Earned Bach degree & $5 \%$ & $7 \%$ \\
\hline FutureHighestDeg & None & $18 \%$ & $12 \%$ \\
(degrees earned not & & & \\
incld) & Associates & $38 \%$ & $28 \%$ \\
& Bachelors & $29 \%$ & $34 \%$ \\
& Masters & $12 \%$ & $19 \%$ \\
& PhD & $3 \%$ & $6 \%$ \\
\hline
\end{tabular}

Another set of questions asked in the survey measure students' knowledge and utilization of campus resources. When looking more closely at Advanced Manufacturing students, we see some interesting patterns. Students appear aware of campus resources such as flexible courses/schedules, online courses, hybrid courses, online textbooks, advising, tutoring, mentoring, career/job placement services, and internship opportunities, yet will say that they do not use these resources. This pattern among Advanced Manufacturing students is consistent with the overall sample's responses to these questions as well. 


\begin{tabular}{|c|c|c|c|c|c|}
\hline Campus Resources & $\begin{array}{l}\text { Not } \\
\text { available, } \\
\text { would not } \\
\text { use }\end{array}$ & $\begin{array}{l}\text { Not } \\
\text { available, } \\
\text { would use }\end{array}$ & $\begin{array}{l}\text { Available, } \\
\text { do not use }\end{array}$ & $\begin{array}{l}\text { Available, } \\
\text { do use }\end{array}$ & $\begin{array}{l}\text { Use among } \\
\text { those who } \\
\text { say it is } \\
\text { Available } \\
\text { (column } \\
3 /(\text { column } 3 \\
+ \text { column } 4 \text { ) }\end{array}$ \\
\hline Flexible courses/schedules & $15 \%$ & $12 \%$ & $38 \%$ & $34 \%$ & $47 \%$ \\
\hline Online courses & $11 \%$ & $5 \%$ & $55 \%$ & $29 \%$ & $35 \%$ \\
\hline Hybrid courses & $33 \%$ & $5 \%$ & $45 \%$ & $17 \%$ & $28 \%$ \\
\hline Online textbooks & $18 \%$ & $12 \%$ & $43 \%$ & $27 \%$ & $39 \%$ \\
\hline Advising & $9 \%$ & $3 \%$ & $49 \%$ & $40 \%$ & $45 \%$ \\
\hline Tutoring services (i.e. writing center) & $9 \%$ & $2 \%$ & $70 \%$ & $18 \%$ & $21 \%$ \\
\hline Mentoring & $26 \%$ & $7 \%$ & $59 \%$ & $8 \%$ & $12 \%$ \\
\hline Career/job placement services & $10 \%$ & $6 \%$ & $60 \%$ & $24 \%$ & $29 \%$ \\
\hline Internship opportunities & $17 \%$ & $9 \%$ & $53 \%$ & $21 \%$ & $28 \%$ \\
\hline Mental health services/counseling & $32 \%$ & $4 \%$ & $59 \%$ & $5 \%$ & $7 \%$ \\
\hline Student resources centers (i.e. multicu & $13 \%$ & $3 \%$ & $68 \%$ & $16 \%$ & $19 \%$ \\
\hline Disability services & $23 \%$ & $2 \%$ & $70 \%$ & $5 \%$ & $6 \%$ \\
\hline Food pantry & $43 \%$ & $6 \%$ & $45 \%$ & $5 \%$ & $11 \%$ \\
\hline Childcare & $43 \%$ & $7 \%$ & $48 \%$ & $3 \%$ & $5 \%$ \\
\hline Financial support & $10 \%$ & $7 \%$ & $60 \%$ & $24 \%$ & $28 \%$ \\
\hline
\end{tabular}

Implications for Recruitment, Retention, and Completion

These findings from the PathTech LIFE Survey reveal many important aspects of technician students' lives and experiences. First, the majority of students have children in their households as well as employed while in their programs. The majority of students indicate appreciation for the way their programs fit into their schedules and lifestyles. Second, the majority of students in the overall sample also indicate interest in completing a degree, commitment to the field, and high levels of program satisfaction. Taken together, this indicates a likelihood that students in technician education programs will be focused on completion as well as opportunities that may allow them to gain entry to jobs in the field, such as internships and co-ops. Third, the socio-demographic data indicates an increasingly diverse student body, including growing numbers of women and racial-ethnic minorities in the programs. Taking these findings together, recommendations for recruitment, retention and completion would include 1) creating programs and policies that support students with families and jobs, 2) create programs and policies that facilitate movement into technician jobs, and 3) create a program climate and environment that is welcoming to students of all social backgrounds.

In looking more closely at students in Advanced Manufacturing programs, we see that greater numbers of students are younger, men, and White, working full-time in manufacturing and aspiring for either no degree or an Associate's degree. These key differences do stand in contrast with the overall sample and require a more tailored approach in developing programs to facilitate recruitment, retention, and completion of programs. 
Finally, when examining students' knowledge and utilization of campus resources, we see similar patterns of under-utilization occurring within the sub-group of Advanced Manufacturing students and the overall sample. This is another key area to implement programmatic change. Utilizing resources such as flexible/online/hybrid courses and advising/career services/mentoring/tutoring will likely increase program retention and completion, as well as entry into the technician field. 
$\checkmark$

Page 7: [2] Deleted 